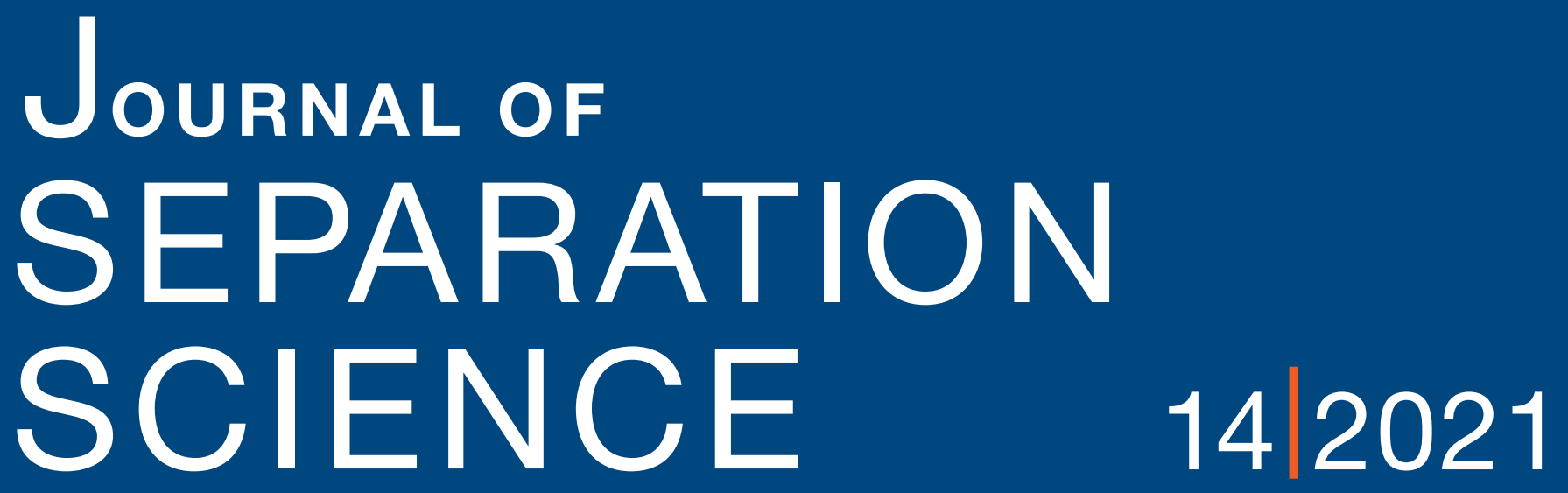

LC-MS/MS-based Targeted Proteomics
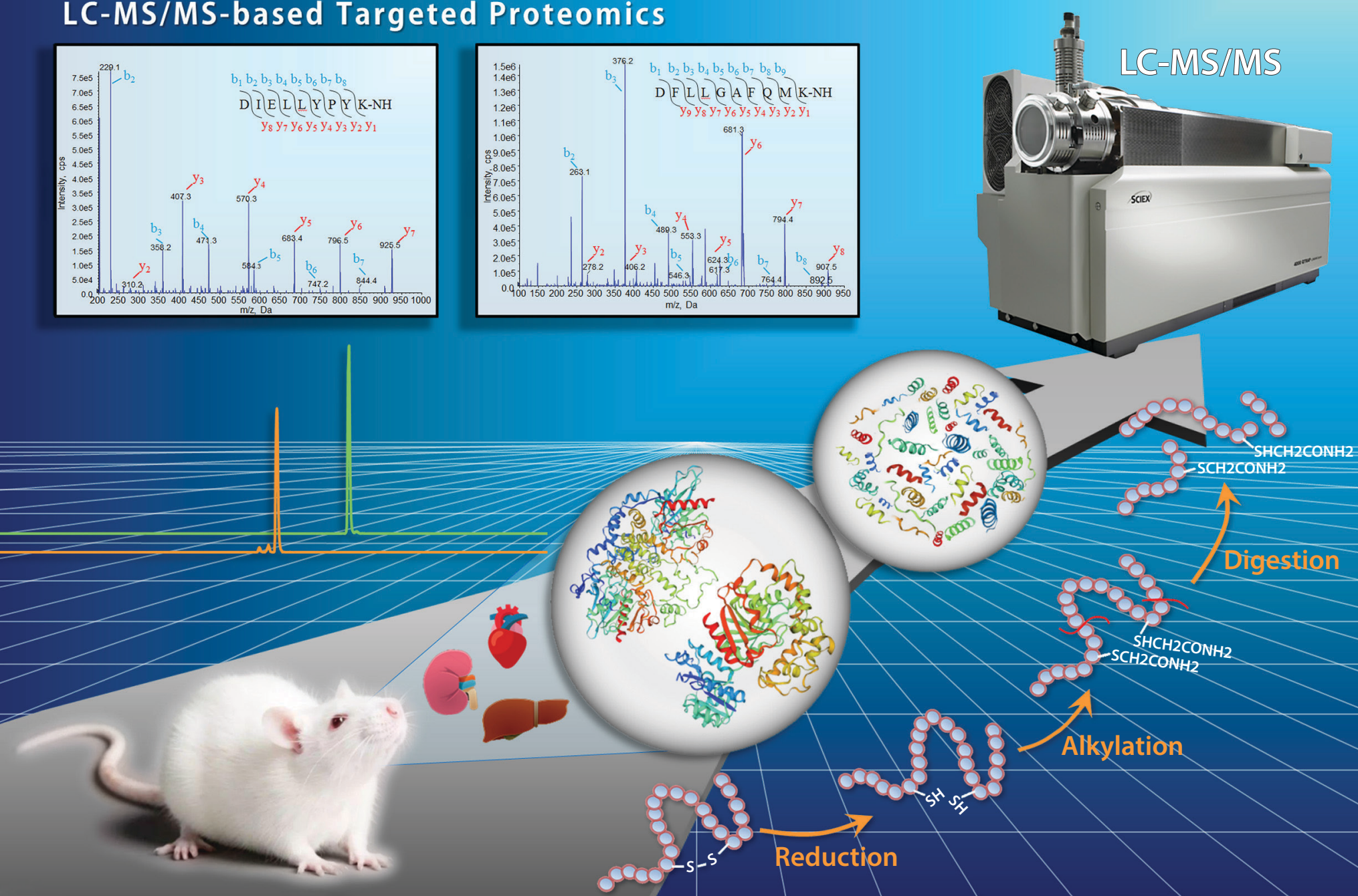

Chromatography Electroseparation
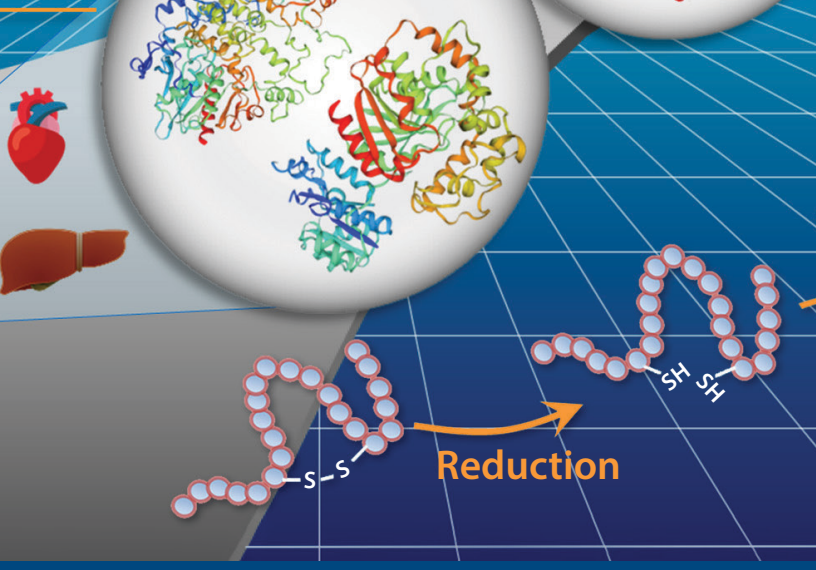


\title{
Cinchona-alkaloid-based zwitterionic chiral stationary phases as potential tools for high-performance liquid chromatographic enantioseparation of cationic compounds of pharmaceutical relevance
}

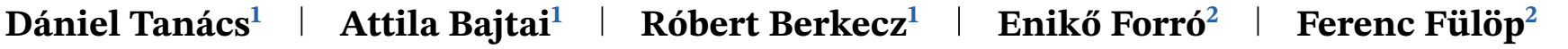 \\ Wolfgang Lindner $^{3} \quad \mid$ Antal Péter $^{1} \quad \mid \quad$ István Ilisz $^{1}$ (])
}

${ }^{1}$ Institute of Pharmaceutical Analysis, Interdisciplinary Excellence Centre, University of Szeged, Szeged, Hungary

${ }^{2}$ Institute of Pharmaceutical Chemistry, Interdisciplinary Excellence Centre, University of Szeged, Szeged, Hungary

${ }^{3}$ Department of Analytical Chemistry, University of Vienna, Vienna, Austria

Correspondence

István Ilisz, Institute of Pharmaceutical Analysis, Interdisciplinary Excellence Centre, University of Szeged, H-6720 Szeged, Somogyi utca 4, Hungary.

Email:ilisz.istvan@szte.hu

\begin{abstract}
Enantiomers of cationic compounds of pharmaceutical relevance, namely tetrahydro- $\$$-carboline and 1,2,3,4-tetrahydroisoquinoline analogs, were separated by high-performance liquid chromatography. Separations were performed on Cinchona-alkaloid-based zwitterionic ion exchanger type chiral stationary phases applied as cation exchangers using mixtures of methanol and acetonitrile or tetrahydrofuran as bulk solvent components containing triethylammonium acetate or ammonium acetate as organic salt additives. On the zwitterionic ZWIX(+) and ZWIX(-) columns investigated, retention and enantioseparation of the studied basic analytes were influenced by the nature and concentration of the organic components of the mobile phase. The effect of organic salt additives on the retention behavior of the studied analytes can be described by the stoichiometric displacement model related to the counterion concentration. Investigations on the structure-retention relationships were performed applying different mobile phase systems for the two types of cationic analytes. For the thermodynamic characterization, parameters such as changes in standard enthalpy $\left(\Delta\left(\Delta H^{\circ}\right)\right)$, entropy $\left(\Delta\left(\Delta S^{\circ}\right)\right)$, and free energy $\left(\Delta\left(\Delta G^{\circ}\right)\right)$ were calculated on the basis of van't Hoff plots derived from the $\ln \alpha$ versus $1 / T$ curves. In most cases, enthalpy-driven enantioseparations were observed, with a consistent dependence of the calculated thermodynamic parameters on the mobile phase composition. Elution sequences of the studied compounds were determined in all cases.
\end{abstract}

\section{KEYWORDS}

chiral stationary phases, enantioselective separation, high-performance liquid chromatography, tetrahydro- $\beta$-carboline analogs, zwitterionic ion-exchangers
Article Related Abbreviations: CSP, chiral stationary phase; FA, formic acid; TEA, triethylamine; THF, tetrahydrofuran; THIQ, 1,2,3,4-tetrahydroisoquinoline; THßC, tetrahydro-ß-carboline

\section{1 | INTRODUCTION}

A large number of compounds containing tetrahydroisoquinoline (THIQ) have important pharmacological 
activity. Anticancer effect is shown by the naturally occurring expectorant emetine [1], antitussive noscapine [2], and trabectidine [3], whereas urinary antispasmodic effect is shown by the synthetic compound solifenacin [4]. The use of compounds containing tetrahydro- $\beta$-carboline $(\mathrm{TH} \beta \mathrm{C})$ in medicine is as important as THIQ derivatives mentioned above. For instance, vincristine, vinblastine [5], and reserpine [6] exhibit antihypertensive and/or antitumor activities. Harmicine [7] has antinociceptive activity, whereas (+)-7-bromotypargine shows antimalarial activity [8]. The THIQ and TH $\beta \mathrm{C}$ derivatives are of great pharmaceutical potential, and attempts to synthesize novel compounds might possibly result in the discovery of effective new drugs. These new chiral compounds demand the development of effective methods offering enantioselectivity for efficient enantioseparation. From the 1990s, enantioseparation of salsolinol and THIQ analogs was performed by gas chromatography, utilizing indirect liquid chromatography applying isothiocyanatebased chiral derivatizing agent, and by direct LC using $ß$-CDs and their derivatives as mobile phase additives or selectors incorporated into stationary phases. Related results are collected in a review paper published recently [9]. Besides B-CDs, selectors based on polysaccharides [9-13], chiral crown ether [14] and, recently, Cinchona alkaloids $[13,15]$ were applied. The relatively few direct chromatographic enantioseparations of chiral TH $\beta \mathrm{C}$ derivatives were performed on chiral stationary phases based on polysaccharides [12,13,16,17], Cinchona alkaloids [13], and strong cation exchangers (CSPs) [17].

Stereoselective interactions are greatly affected by the temperature in chiral separations [18-20]. Thermodynamic parameters derived from temperature-dependence studies can provide valuable information about processes that play key roles in the retention mechanism. It is important to emphasize that the thermodynamic data presented here cover apparent values from a combination of enantioselective and nonselective interactions. Nevertheless, by a careful interpretation of the van't Hoff equation, thermodynamic parameters obtained under the same conditions (given stationary phase, mobile phase with constant composition, constant flow rate) still can provide useful information for a better understanding of the mechanism in the case of structurally related compounds. The difference in the change in standard enthalpy $\left(\Delta\left(\Delta H^{\circ}\right)\right)$ and entropy $\left(\Delta\left(\Delta S^{\circ}\right)\right)$ for the two enantiomers can be calculated on the basis of Eq. (1) [19-22],

$$
\ln \alpha=-\frac{\Delta\left(\Delta H^{\circ}\right)}{R T}+\frac{\Delta\left(\Delta S^{\circ}\right)}{R},
$$

where $R$ is the universal gas constant, $T$ is temperature in Kelvin, and $\alpha$ is the apparent selectivity factor. All possibilities and problems of calculation of the thermodynamic parameters were excellently summarized by Asnin and Stepanova [20].

In our earlier study, employing strong cation exchangerbased CSPs revealed some interesting peculiarities regarding the enantioseparation of THIQ and TH $\beta C$ derivatives [23]. Since the efficient enantioseparation of THIQ analogs could not be achieved, here, a detailed study applying Cinchona-alkaloid-based zwitterionic chiral ion exchangers has been carried out. The focus of the present report is on the investigation of the effects of the nature and concentration of mobile phase components and the concentration of the counterion on the chromatographic performance. The specific structural features of analytes and selectors and the effect of temperature on chromatographic behavior and thermodynamic parameters were also studied. The elution sequence was determined in all cases.

\section{2 | MATERIALS AND METHODS}

\section{1 | Chemicals and reagents}

Enantiomers of 1-methyl- (1A and $\mathbf{1 B})$, 1-ethyl- (2A and 2B), 1-propyl- (3A and 3B) TH $\beta C$, and 1-methyl- (4A and 4B), 1-ethyl- (5A and 5B), 1-propyl- (6A and 6B) THIQ were prepared through Candida antarctica lipase B-catalyzed asymmetric $N$-alkoxycarbonylations with phenyl allyl carbonate of racemic 1-substituted THIQ and $\mathrm{TH} \beta \mathrm{C}$ in diisopropyl ether $\left(i \mathrm{Pr}_{2} \mathrm{O}\right)$ at $60^{\circ} \mathrm{C}(E>200)$ [24,25] (Figure 1). Both the unreacted $(S)$ enantiomers (1B-6B) and their antipodes $(\mathbf{1 A}-\mathbf{6 A})$, prepared through hydrolysis of $(R)$-carbamates in enzymatic reactions, were obtained with high enantiomeric excess $(>97 \%)$.

Organic components of mobile phases such as acetonitrile $(\mathrm{MeCN})$, methanol $(\mathrm{MeOH})$, tetrahydrofuran (THF) of HPLC grade, and ammonium acetate $\left(\mathrm{NH}_{4} \mathrm{OAc}\right)$, triethylamine (TEA), formic acid (FA), and acetic acid $(\mathrm{AcOH})$ of analytical reagent grade were obtained from VWR International (Radnor, PA, USA). All analytes were dissolved in $\mathrm{MeOH}$ in the concentration range $0.5-1.0 \mathrm{mg} / \mathrm{mL}$ and injected in a volume of $20 \mu \mathrm{L}$.

\section{2 | Apparatus and chromatography}

Chromatographic measurements were carried out on a Waters Breeze system consisting of a 1525 binary pump, a 2996 photodiode array detector, a 717 plus autosampler, and Empower 2 data manager software (Waters, Milford, MA, USA). A Lauda Alpha RA8 thermostat (Lauda Dr. R. Wobser Gmbh, Lauda-Königshofen, 


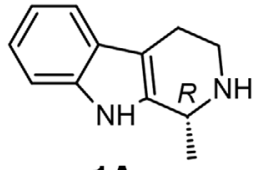

$1 \mathrm{~A}$

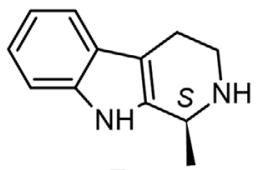

1B
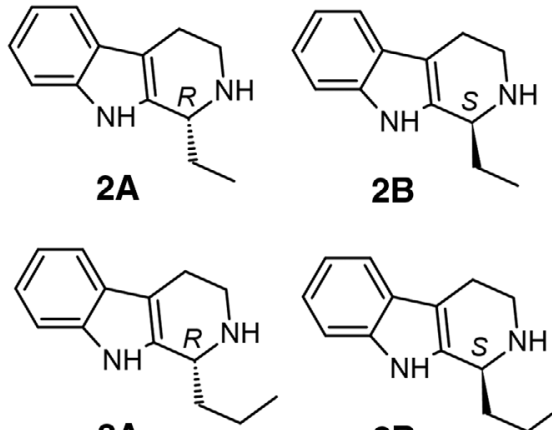

3A

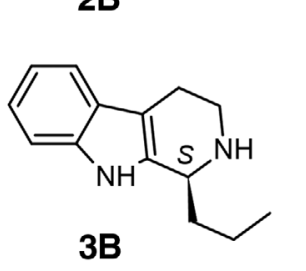<smiles>COc1cc2c(cc1OC)[C@H](C)NCC2</smiles>

$4 \mathrm{~A}$<smiles>CC[C@@H]1NCCc2cc(OC)c(OC)cc21</smiles>

5A<smiles>CCC[C@@H]1NCCc2cc(OC)c(OC)cc21</smiles>

6A<smiles>COc1cc2c(cc1OC)C(C)NCC2</smiles>

$4 B$<smiles>[B]C[C@@H]1NCCc2cc(OC)c(OC)cc21</smiles>

$5 \mathrm{~B}$<smiles>CCCC1NCCc2cc(OC)c(OC)cc21</smiles>

6B

F I G URE 1 Structure of analytes

Germany) was employed to maintain constant column temperature.

Cinchona-alkaloid-based zwitterionic columns, namely the quinine-based $\mathrm{ZWIX}(+)$ and the quinidine-based ZWIX(-), were obtained from Chiral Technologies Europe (Illkirch, France); their structures are depicted in Supporting Information Figure S1. All employed columns have the same physical size $(150 \times 3.0 \mathrm{~mm}$ id, $3-\mu \mathrm{m}$ particle size). The dead times of the columns were determined by injection of acetone dissolved in $\mathrm{MeOH}$. Experiments, unless otherwise stated, were carried out in isocratic mode at a flow rate of $0.6 \mathrm{~mL} / \mathrm{min}$ and column temperature of $25^{\circ} \mathrm{C}$.

\section{3 | RESULTS AND DISCUSSIONS}

The investigated TH $\beta \mathrm{C}$ and THIQ analogs under slightly acidic conditions behave as cationic compounds (the calculated $\mathrm{p} K_{\mathrm{a}}$ values for analytes 1-6 are 9.16, 9.29, 9.30, 8.89, 9.04, and 9.06, respectively; calculations were done by Marvin Sketch v. 17.28 software, ChemAxon Ltd., Budapest). The structural differences of tetrahydro$ß$-carboline (THßC) and THIQ analogs with three- and two-ring systems, bearing methoxy groups on the latter, and an alkyl (methyl, ethyl, propyl) substitution in both types of analytes may provide differences in chromatographic behavior. In view of their chemical nature and ampholitic property, we intended to explore the efficiency of the chiral zwitterionic ZWIX columns applied as cation exchangers for the given chiral cationic analytes.

\section{1 | Mobile phase selection}

ZWIX(+) and ZWIX(-) columns are frequently used with $\mathrm{MeOH}$ as protic polar bulk solvent (which can modify $\mathrm{H}$-bond interactions) and $\mathrm{MeCN}$ or THF as aprotic, but polar bulk solvents (which can support ion-pair formation, but they interfere with $\pi-\pi$ interactions) in combination with organic acid (FA or AcOH) and base additives (TEA or ammonia) [15]. The effects of the composition of the bulk solvent on chromatographic parameters on zwitterionic columns are depicted in Figure 2 [for ZWIX(-)] and in Supporting Information Figure S2 [for ZWIX(+)]. In the $\mathrm{MeOH} / \mathrm{MeCN}(100 / 0-10 / 90 \mathrm{v} / \mathrm{v})$ mobile phases containing $25 \mathrm{mM}$ TEA and $50 \mathrm{mM}$ FA, for the $k_{1}$ values of all studied analytes, a significant increase was registered with increasing $\mathrm{MeCN}$ content (Figure 2A and Supporting Information Figure S2A). The observed changes in the retentions of THßC analogs were slightly higher, compared to those of the THIQ analogs. These mobile phase systems were only slightly effective in the enantioseparation of THßC and THIQ analogs, and gave moderate $\alpha$ and $R_{S}$ values only for analytes 1 and 4 (enantiomers of analyte 5 were not separable under these conditions).

The change of MeCN to THF has a significant effect on the chromatographic performance similar to that observed earlier [26]. Starting with a mobile phase containing $100 \%$ $\mathrm{MeOH}$ (and $25 \mathrm{mM}$ TEA and $50 \mathrm{mM} \mathrm{FA}$ ), $k_{1}$ increased substantially with increasing THF content, especially in the cases of analytes 1 and 4 (Figure 2B and Supporting Information Figure $\mathrm{S} 2 \mathrm{~B})$. As concerns $\alpha$ and $R_{S}$ values, they changed in different ways compared to $\mathrm{MeOH} / \mathrm{MeCN}$ mobile phases. Namely, they increased substantially with 


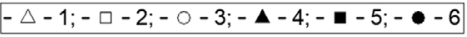

A
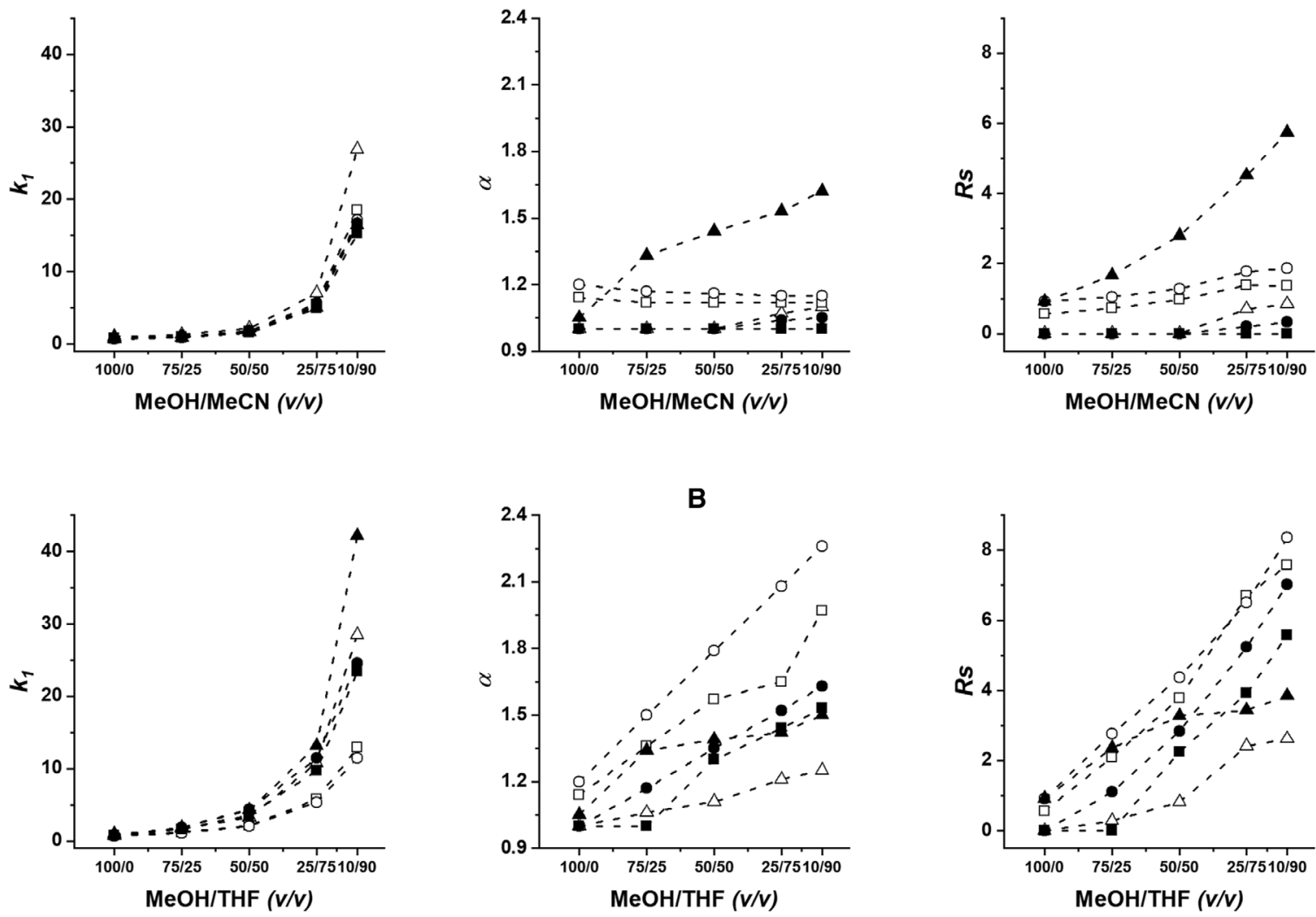

F I G U R E 2 Effects of the bulk solvent composition on the retention factor of the first eluting enantiomer $\left(k_{1}\right)$, the separation factor $(\alpha)$, and the resolution $\left(R_{S}\right)$ for analytes 1-6 chromatographic conditions: column, ZWIX(-); mobile phase, A, MeOH/MeCN (100/0, 75/25, 50/50, 25/75, and 10/90, v/v) all containing $25 \mathrm{mM}$ TEA and $50 \mathrm{mM} \mathrm{FA}$ and B, MeOH/THF (100/0, 75/25, 50/50, 25/75, and 10/90, v/v) all containing $25 \mathrm{mM}$ TEA and $50 \mathrm{mM} \mathrm{FA}$; flow rate, $0.6 \mathrm{~mL} / \mathrm{min}$; detection, $220-250 \mathrm{~nm}$; temperature, $25^{\circ} \mathrm{C}$; symbols: for analyte $\mathbf{1}, \triangle$, for $\mathbf{2}, \square$, for 3, $\bigcirc$, for $\mathbf{4}, \mathbf{4}$, for $\mathbf{5}, \mathbf{\square}$, for $\mathbf{6}$,

increasing THF content especially on ZWIX(-) CSP, while on ZWIX(+) CSP the enhancement in $\alpha$ and $R_{S}$ values was smaller and analyte 1 was separable only at the highest THF content.

The marked increase of retention with increasing $\mathrm{MeCN}$ or THF in both mobile phase systems can be attributed to the decreased solvation effect of both the polar cationic analytes and the zwitterionic selectors. In mobile phases rich in MeCN or THF, solvation of polar compounds and charged sites decreased, thus, the electrostatically driven interaction between selector and selectand enhanced. With variation of the type of bulk solvents, $\alpha$ and $R_{S}$ values can be improved.

\section{2 | Effect of the counterion concentration}

To provide evidence of ionic interactions taking place in the separation, the stoichiometric displacement model is most often applied [27]. According to this model, the presence of co- and counterions in the mobile phase influence the retention behavior and the logarithm of the retention factor is linearly related to the logarithm of the counterion concentration,

$$
\log k=\log K_{Z}-Z \log c_{\text {counterion }}
$$

where $Z=m / n$ is the ratio of the number of charges of the cation and the counterion, and $K_{z}$ is related to the ionexchange equilibrium constant. If ionic interaction takes place, the $\log k$ versus $\log c_{\text {counterion }}$ function shows a linear relationship, where the slope of the line is proportional to the effective charge during ion exchange, while the intercept carries information about the equilibrium constant of ion exchange.

Applying a mobile phase of $\mathrm{MeOH} / \mathrm{MeCN}(50 / 50, \mathrm{v} / \mathrm{v})$ or $\mathrm{MeOH} / \mathrm{THF}(50 / 50, \mathrm{v} / \mathrm{v})$ in the presence of TEA/FA at concentrations of 6.125/12.5, 12.5/25, 25/50, 50/100, and 
TA B LE 1 Comparison of the effect of MeCN and THF content in $\mathrm{MeOH}$ as bulk solvent and of formic acid content on the chromatographic data, $k_{1}, \alpha$, and $R_{S}$ of tetrahydro-ß3-carboline and 1,2,3,4-tetrahydroisoquinoline analogs on zwitterionic chiral stationary phases

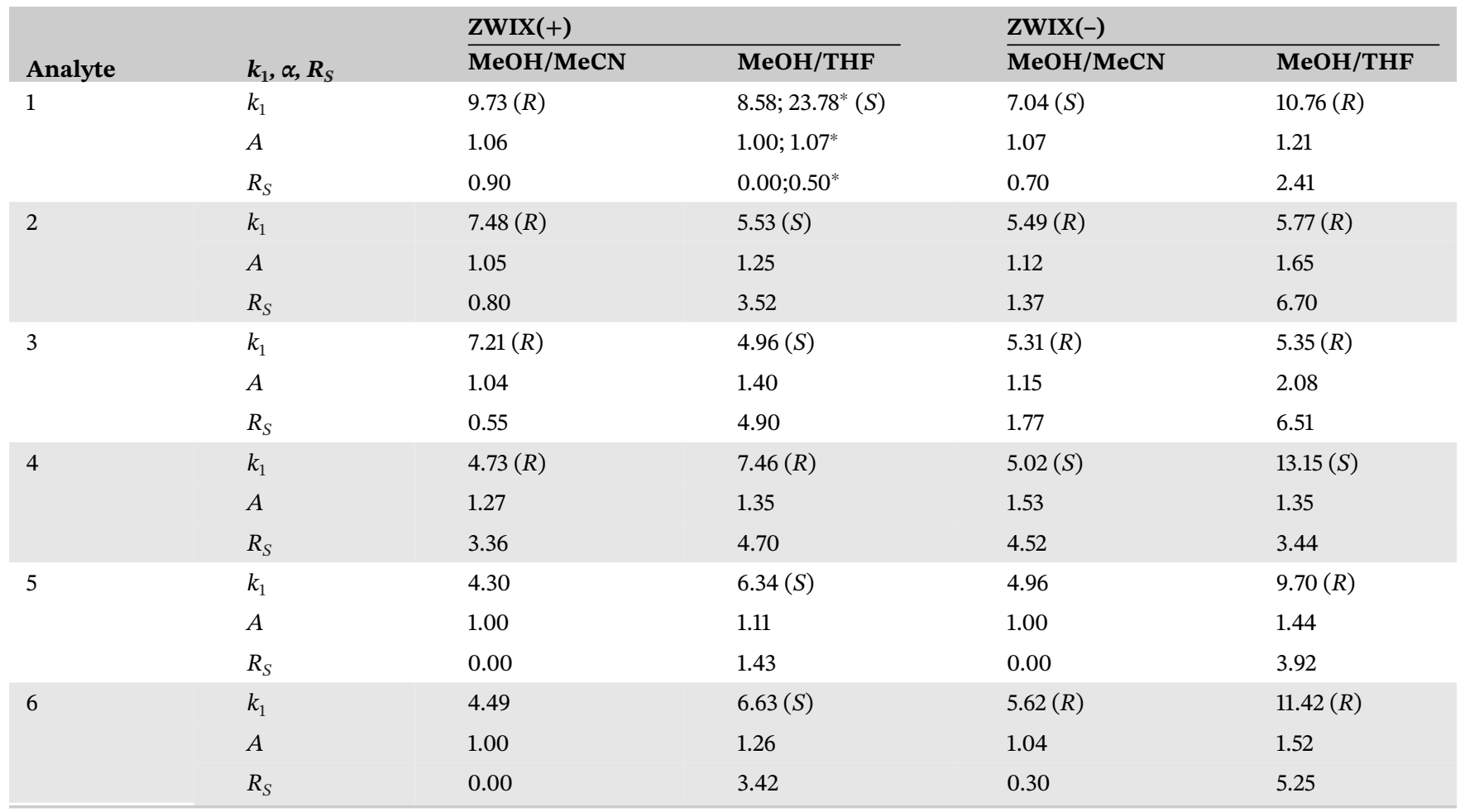

Chromatographic conditions: columns, ZWIX(+) and ZWIX(-); mobile phase, MeOH/MeCN or MeOH/THF (25/75, v/v) and * MeOH/THF (10/90, v/v) all containing $25 \mathrm{mM}$ TEA and $50 \mathrm{mM}$ FA; flow rate, $0.6 \mathrm{~mL} / \mathrm{min}$; detection at 223 or $230 \mathrm{~nm}$; temperature, $25^{\circ} \mathrm{C}$; $(R)$ or $(S)$, configuration of the first eluting enantiomer.

$100 / 200 \mathrm{mM} / \mathrm{mM}$, the protonated triethylammonium ion acts as a competitor in the ion-pairing process. The effects of variation of the concentration of the counterion on retention for analytes 1-6 on ZWIX(+) and ZWIX(-) CSPs are depicted in Supporting Information Figure S3. Under the studied conditions, linear relationships were found between $\log k_{1}$ versus $\log c_{\text {counterion, with slopes }}$ varying between $(-0.50)-(-0.70)$ and $(-0.35)-(-0.52)$ on ZWIX(+) and ZWIX(-) CSPs, respectively. The observed slopes correspond well to the values found earlier by Grecsó et al. for trans-paroxetin [26] and by Lajkó et al for C-protected amino acids examined on zwitterionic selector acting as cation-exchanger-type CSP [28]. Under the applied conditions, practically identical slopes were obtained for each enantiomer, that is, the enantioselectivity remained almost constant (no data presented).

\section{3 | Structure-retention relationships and elution sequences}

Our primary goal was to explore the relationships between the molecular structure of sample compounds and their chromatographic properties. The methyl, ethyl, and propyl substituents on both types of analytes endow the molecules with different sizes. The so-called size descriptor $\left(V^{a}\right)$ introduced by Meyer characterizes the steric effect of the substituent on the reaction rate [29]. In order to gain a deeper understanding of the effect of alkyl substituents, the relationship between the Meyer parameter and retention (and selectivity) was explored. The effect of alkyl side chain was studied on ZWIX(+) and ZWIX(-) CSPs with mobile phases $\mathrm{MeOH} / \mathrm{MeCN}$ and $\mathrm{MeOH} / \mathrm{THF}(10 / 90, \mathrm{v} / \mathrm{v})$, both containing $25 \mathrm{mM}$ TEA and $50 \mathrm{mM}$ FA. According to Supporting Information Figure S4, for analytes 1-3, retention markedly depends on the volume of the alkyl side chain and a linear relationship could be registered for $k_{1}$ versus $V^{a}$, with good correlation. With increasing size of the molecule retention decreased, while selectivity increased. That is, a bulkier substituent, via steric effects, slightly inhibited nonselective but improved selective interactions formed between analyte and selector. It is important to mention that the elution order was not influenced by the size of the substituent.

The sterically demanding structures of the analytes (Figure 1) affect retention and chiral recognition. Table 1 reports the $k_{1}, \alpha$, and $R_{S}$ values with the most frequently applied mobile phases on ZWIX(+) and ZWIX(-) CSPs. The comparison of separation performances of THßC and THIQ analogs reveals that THßC derivatives and 
the methyl-substituted THIQ analog (4) could efficiently be separated on ZWIX(+) and ZWIX(-) CSPs in the $\mathrm{MeOH} / \mathrm{THF}$ mobile phase system, while the $\mathrm{MeOH} / \mathrm{MeCN}$ mobile phase exhibited poorer separation efficiency (the only exception was analyte 4). The THIQ analogs were less retained than the THßC derivatives in $\mathrm{MeOH} / \mathrm{MeCN}$ mobile phases, while in the $\mathrm{MeOH} / \mathrm{THF}$ system they were more efficiently retained and, in general, baseline separation could be achieved (Table 1). Applying $\mathrm{MeOH} / \mathrm{MeCN}(25 / 75$, v/v), mobile phases containing $\mathrm{NH}_{4} \mathrm{OAc}$ as additive instead of triethylammonium acetate similar retention behavior was observed: $k_{1}$ decreased with increasing bulkiness of the side chain of the analytes. In this case, analytes eluted with retention times three to four times lower than in the case of triethylammonium acetate. This behavior is probably attributed to the difference of size and elution strength of the ammonium and triethylammonium ion. It is interesting to note here that separation factors practically remained constant (ranged between 1.05 and 1.13), and rather poor resolutions were registered (Supporting Information Table S1). It must be mention that application of AcOH instead of FA has only a slight effect on the $k_{1}, \alpha$, and $R_{S}$ values (data not shown).

The chiral selectors of Chiralpak ZWIX(+) and ZWIX(-) columns are actually diastereomeric to each other (Supporting Information Figure S1), but in most cases behave like pseudo-enantiomers [30]. As a consequence, upon changing from the quinine-based to the quinidine-based CSP, a reversal of the elution sequence generally takes place. This expectation proved to be valid in the $\mathrm{MeOH} / \mathrm{THF}$ mobile phase system. However, in $\mathrm{MeOH} / \mathrm{MeCN}$ mobile phases, the reversal of elution sequence was registered only for analytes 1 and 4 , while in the case of analytes 2,3 , and 6 , the configuration of the first eluting enantiomer on both ZWIX(+) and ZWIX(-) was $(R)$; analyte 5 was not separable under these conditions (Table 1).

\section{4 $\quad$ Temperature dependence and thermodynamic study}

Asnin and co-workers have recently studied the enantioseparation of some dipeptides applying macrocyclic antibiotic-based CSPs and reported correlation between $\Delta H^{\circ}, \Delta S^{\circ}$ or $\Delta G^{\circ}$ and the $\mathrm{pH}$ or $\mathrm{MeOH}$ content of the mobile phase $[21,22]$. To characterize the employed systems from a thermodynamic point of view, the effect of temperature on the chromatographic parameters in the temperature range $10-50^{\circ} \mathrm{C}$ (at $10^{\circ} \mathrm{C}$ increments) was studied. ZWIX $(-)^{\mathrm{TM}}$ column and conditions ensuring the best separation performances, namely, $\mathrm{MeOH} / \mathrm{THF}$ and $\mathrm{MeOH} / \mathrm{MeCN}$ mobile phase systems with varying ratios of organic solvent components between $90 / 10$ and 10/90 (v/v) were applied with a constant acid-to-base ratio (FA/TEA, 50/25 mM/mM). The experimental data are listed in Supporting Information Tables S2-S4, while the calculated thermodynamic parameters are depicted in Supporting Information Table S5 and Figure 3.

Surveying the data for the $\mathrm{MeOH} / \mathrm{THF}$ mobile phase system (Supporting Information Tables S2, S3, and S5), a marked difference in chromatographic and thermodynamic parameters for analytes 2-6 versus 1 can be revealed. The transfer of the analyte from the mobile to the stationary phase is commonly an exothermic process with $\alpha$ decreasing with increasing temperature. This trend was observed for analytes $\mathbf{2 - 6}$. The calculated thermodynamic parameters were all negative and varied in a range from -0.48 to $-3.73 \mathrm{~kJ} \mathrm{~mol}^{-1}$ for $\Delta\left(\Delta H^{\circ}\right)$, and from -0.14 to $-9.23 \mathrm{~J} \mathrm{~mol}^{-1} \mathrm{~K}^{-1}$ for $\Delta\left(\Delta S^{\circ}\right)$. The negative $\Delta\left(\Delta H^{\circ}\right)$ values indicate that the adsorption is preferential in view of the enthalpy term, while it is unfavorable in view of the entropy term. The $\Delta\left(\Delta S^{\circ}\right)$ values are governed by the difference in the number of degrees of freedom between the stereoisomers on the CSP, and mainly by the number of solvent molecules released from the chiral selector and the analyte, when the analyte is associated with the CSP. The trends in the change in $\Delta\left(\Delta S^{\circ}\right)$ and $\Delta\left(\Delta H^{\circ}\right)$ were similar, that is, the more negative $\Delta\left(\Delta H^{\circ}\right)$ was accompanied with a more negative $\Delta\left(\Delta S^{\circ}\right)$. Analyte $\mathbf{1}$ (possessing a methyl substituent) exhibited different behavior. In this case, selectivity increases with increasing temperature, and the calculated $\Delta\left(\Delta H^{\circ}\right)$ and $\Delta\left(\Delta S^{\circ}\right)$ are positive. The positive $\Delta\left(\Delta S^{\circ}\right)$ value compensates the positive $\Delta\left(\Delta H^{\circ}\right)$ value resulting in a negative $\Delta\left(\Delta G^{\circ}\right)$, that is, the enantioseparation is still thermodynamically favorable (Supporting Information Table S5 and Figure 3).

Investigation of the effect of THF content on thermodynamic characteristics in the $\mathrm{MeOH} / \mathrm{THF}$ bulk solvent system showed that for analytes 2, 3, 5, and $\mathbf{6}$, the increase of THF concentration resulted in more negative $\Delta\left(\Delta H^{\circ}\right)$ and $\Delta\left(\Delta S^{\circ}\right)$ values. Furthermore, it is important to highlight the more negative $\Delta\left(\Delta G^{\circ}\right)$ values, because enantioseparation becomes thermodynamically more favorable and both enantioselectivity and resolution are improved (Supporting Information Table S5 and Figure 3). The increasing negative values of the four analogs with increasing THF content suggest that the solvation of ionic analytes in THF-rich bulk solvents decreases, and retention and selectivity enhance. These phenomena are due to the difference between the sum of the enantioselective and nonselective processes related to the adsorption and desorption steps of the enantiomers.

Interestingly, methyl-substituted analytes $\mathbf{1}$ and 4 behaved differently. The deviation from the 

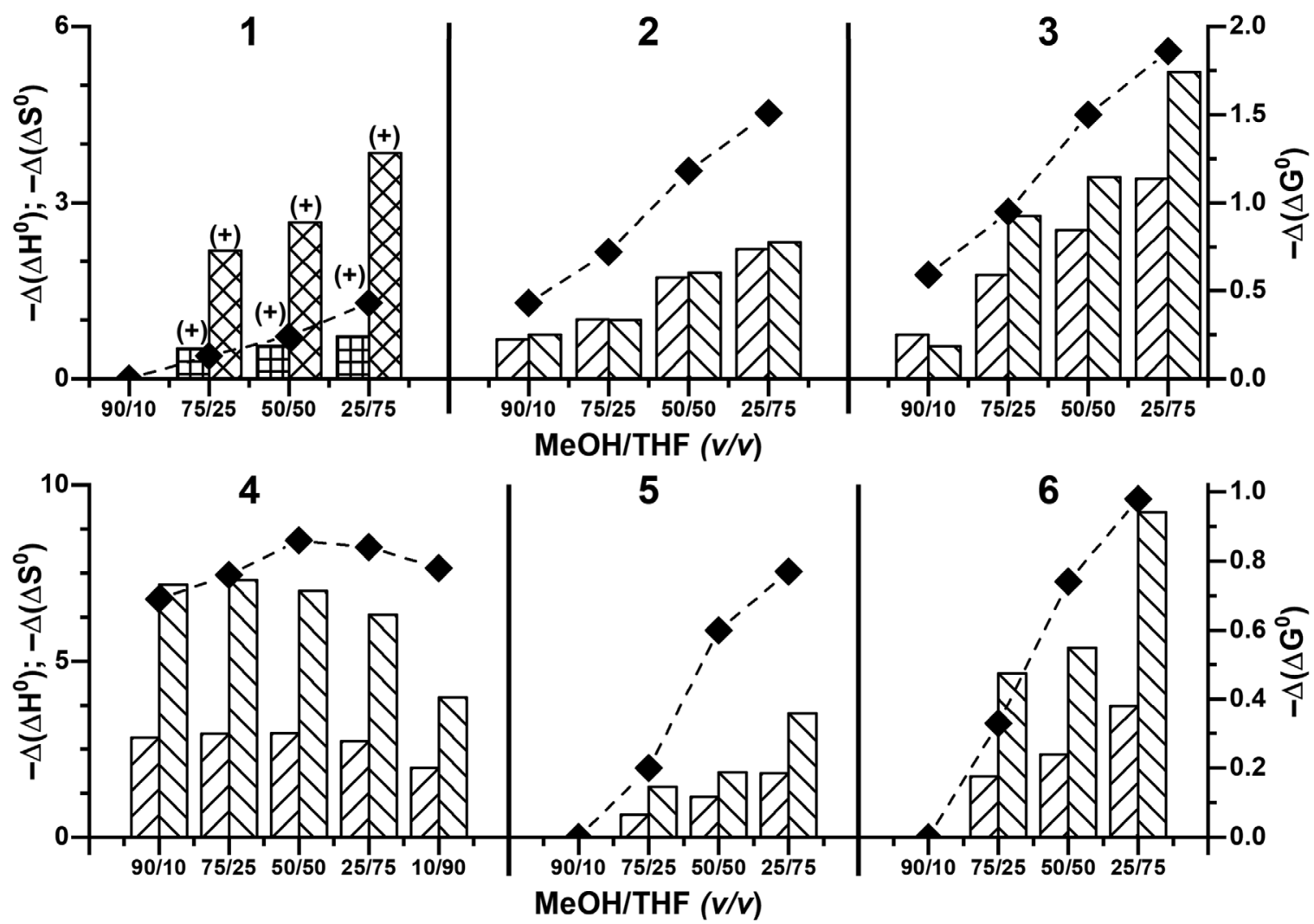

F I G U R E 3 Thermodynamic parameters, $\Delta\left(\Delta H^{\circ}\right), \Delta\left(\Delta S^{\circ}\right)$, and $\Delta\left(\Delta G^{\circ}\right)$ of THßC and THIQ analogs on ZWIX(-) column chromatographic conditions: columns, ZWIX(-); mobile phase, MeOH/THF (90/10, v/v), MeOH/THF (75/25, v/v), MeOH/THF (50/50, v/v), and $\mathrm{MeOH} / \mathrm{THF}(25 / 75, \mathrm{v} / \mathrm{v})$ all containing $50 \mathrm{mM}$ FA and $25 \mathrm{mM}$ TEA; flow rate, $0.6 \mathrm{~mL} / \mathrm{min}$; detection, 218-280 nm; symbols:

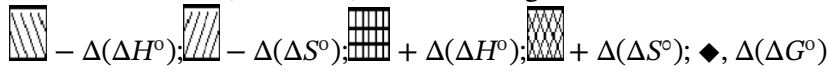

above-mentioned behavior of analyte $\mathbf{1}$ and $\mathbf{4}$ is manifested in two ways. For analyte $1, \alpha$ increased with increasing temperature and THF content, that is, $\Delta\left(\Delta H^{\circ}\right)$ and $\Delta\left(\Delta S^{\circ}\right)$ values became more positive. In contrast to analytes $\mathbf{2}, \mathbf{3}, \mathbf{5}$, and $\mathbf{6}$, for analyte $\mathbf{4} k_{1}$ increased, while $\alpha$ exhibited a slight maximum with increasing THF content. However, $k_{1}$ and $\alpha$ decreased with increasing temperature. As a result of these two effects, $\Delta\left(\Delta H^{\circ}\right)$ and $\Delta\left(\Delta S^{\circ}\right)$ values become slightly less negative, and the $\Delta\left(\Delta G^{\circ}\right)$ value shows a slight maximum with increasing THF content (Figure 3 and Supporting Information Table S5). It should be noted that $\Delta\left(\Delta G^{\circ}\right)$ values for analyte $\mathbf{4}$ are much less dependent on the THF content, and they exhibit relatively high values. The different behavior of analytes $\mathbf{1}$ and $\mathbf{4}$ possessing a methyl substituent sheds light on the importance of steric effect in the discrimination mechanism.

Investigating the $\mathrm{MeOH} / \mathrm{MeCN}$ mobile phases, it can unambiguously be stated that the change of THF to $\mathrm{MeCN}$ in the bulk solvent led to a less effective separation system for both types of analytes; analytes 1,5 , and 6 practically were not separable, while 2 and 3 exhibited only partial separation. Analyte 4, again, behaved in a different way. Its quite high $\alpha$ values were markedly increased with decreas- ing temperature, and in contrast to $\mathrm{MeOH} / \mathrm{THF}$ bulk solvent systems, the $\Delta\left(\Delta H^{\circ}\right)$ and $\Delta\left(\Delta S^{\circ}\right)$ values become more negative with increasing $\mathrm{MeCN}$ content (Supporting Information Table S5). This fact indicates the serious effects of bulk solvent composition on thermodynamic parameters.

The relative contribution of the enthalpic and entropic terms to the free energy of adsorption is reflected in the enthalpy/entropy ratios $Q=\Delta\left(\Delta H^{\circ}\right) / 298 \times \Delta\left(\Delta S^{\circ}\right)$ (Supporting Information Table S5). Except for analyte 1, where $Q<1.0$ was registered in the $\mathrm{MeOH} / \mathrm{THF}$ eluent system, in all other studied cases, $Q$ was higher than 1.0, that is, separations were enthalpically driven independently from the applied mobile phase systems.

Typical chromatograms for the enantioseparation of tetrahydro- $\beta$-carboline and 1,2,3,4-tetrahydroisoquinoline analogs are depicted in Supporting Information Figure S5.

\section{4 | CONCLUDING REMARKS}

Enantioseparation of newly synthesized THßC and THIQ analogs was performed on Cinchona-alkaloid-based zwitterionic CSPs applying $\mathrm{MeOH} / \mathrm{THF}$ and $\mathrm{MeOH} / \mathrm{MeCN}$ 
mobile phases containing TEA and FA (or $\mathrm{NH}_{4} \mathrm{OAc}$ ) additives. The increase of the less polar, aprotic THF, or MeCN in the bulk solvent considerably enhanced retention, selectivity, and resolution, in particular, when applying THF as bulk solvent component. The change of concentration of salt additives moderately affects retention, and according to the stoichiometric displacement model, an ion-exchange mechanism exists, while selectivity practically was independent from the salt content. Investigation of structure-retention (selectivity) relationships revealed that for THßC analogs, both $k_{1}$ and $\alpha$ strongly depend on the size of molecules. Specifically, the bulkier molecules hinder the interaction with the selector, while alkyl substituents with larger volume promote the chiral discrimination. A comparison of separation performances of THßC and THIQ molecules in parallel with application of $\mathrm{MeOH} / \mathrm{THF}$ or $\mathrm{MeOH} / \mathrm{MeCN}$ bulk solvents showed that in the $\mathrm{MeOH} / \mathrm{THF}$ system, all analytes were separated effectively, while $\mathrm{MeOH} / \mathrm{MeCN}$ as bulk solvent was effective only in the chiral discrimination of THßC analogs and the methyl-substituted THIQ analog (4). According to the detailed temperature-dependent study carried out in $\mathrm{MeOH} / \mathrm{THF}$ and $\mathrm{MeOH} / \mathrm{MeCN}$ mobile phase systems, separations, in most cases, were enthalpically controlled, while entropy-controlled separation was observed only for analyte $\mathbf{1}$. The change of thermodynamic parameters $\left[\Delta\left(\Delta H^{\circ}\right), \Delta\left(\Delta S^{\circ}\right)\right.$, and $\left.\Delta\left(\Delta G^{\circ}\right)\right]$ with the variation of mobile phase composition strongly depends on the nature of analyte. In most cases, with the increase of the amount of less polar, aprotic component (THF or $\mathrm{MeCN})$ in the bulk solvent, $\Delta\left(\Delta H^{\circ}\right)$ and $\Delta\left(\Delta S^{\circ}\right)$ values become more negative. The characteristic reversed elution order of the pseudoenantiomeric ZWIX(+) and ZWIX(-) was only registered in the $\mathrm{MeOH} / \mathrm{THF}$ mobile phase systems.

\section{ACKNOWLEDGMENTS}

This work was supported by the project grant GINOP-2.3.215-2016-00034 by the National Research Development and Innovation Office, and the UNNK-20-3 New National Excellence Program of the Ministry for Innovation and Technology from the Source of National Research, Development and Innovation Fund. The Ministry of Human Capacities, Hungary grant TKP-2020 and the grant of Hungarian Scientific Research Council (OTKA, K129049) is also acknowledged.

\section{CONFLICT OF INTEREST}

The authors have declared no conflict of interest.

\section{OR C I D}

István Ilisz @ https://orcid.org/0000-0001-8282-457X

\section{REFERE N C ES}

1. Boyd EM, Knight LM. The expectorant action of cephaeline, emetine and 2-dehydroemetine. J Pharm Pharmacol. 1964;16:118-24.

2. Al-Yahya MA Hassan MMA. Noscapine. Anal Profiles Drug Subst Excipients 1982;11:407-61.

3. Poveda A, Ray-Coquard I, Romero I, Lopez-Guerrero JA, Colombo N. Emerging treatment strategies in recurrent platinum-sensitive ovarian cancer: Focus on trabectedin. Cancer Treat Rev. 2014;40:366-75.

4. Ruff BM, Bräse S, O'Connor SE. Biocatalytic production of tetrahydroisoquinolines. Tetrahedron Lett. 2012;53:1071-4.

5. Zhang ZJ, Yang J, He J, Wu XD, Shao LD, Li Y, Huang SX, Li RT, Zhao QS. Vincamajorines A and B, monoterpenoid indole alkaloids with new carbon skeletons from Vinca major. Tetrahedron Lett. 2014;55:6490-4.

6. Pandey DK, Radha DA. A validated and densitometric HPTLC method for the simultaneous quantification of reserpine and ajmalicine in Rauvolfia serpentina and Rauvolfia tetraphylla. Rev Bras Farmacogn. 2016;26:553-7.

7. Davis RA, Duffy S, Avery VM, Camp D, Hooper JNA, Quinn RJ. (+)-7-Bromotrypargine: An antimalarial $\beta$-carboline from the Australian marine sponge Ancorina sp. Tetrahedron Lett. 2010;51:583-5.

8. Xiao S, Shi XX, Xing J, Yan JJ, Liu SL, Lu WD. Synthesis of tadalafil (Cialis) from 1-tryptophan. Tetrahedron Asymmetry 2009;20:2090-6.

9. Grecsó N, Ilisz I, Gecse Z, Schönstein L, Fülöp F, Péter A. High-performance liquid chromatographic enantioseparation of amino alcohol analogues possessing 1,2,3,4tetrahydroisoquinoline skeleton on polysaccharide-based chiral stationary phases. Biomed Chromatogr. 2015;29:788-96.

10. Kažoka H, Rotkaja O, Varačeva L. Enantioseparation of 1phenyl-1,2,3,4-tetrahydroisoquinoline on polysaccharide-based chiral stationary phases. Chromatographia 2011;73:123-9.

11. Ilisz I, Gecse Z, Szatmári I, Fülöp F, Péter A. High-performance liquid chromatographic enantioseparation of naphtholsubstituted tetrahydroisoquinolines on. polysaccharide-based chiral stationary phases. Biomed Chromatogr. 2014;28:142-51.

12. Bajtai A, Lajkó G, Németi G, Szatmári I, Fülöp F, Péter A, Ilisz I. High-performance liquid chromatographic and subcritical fluid chromatographic separation of $\alpha$-arylated $\beta$-carboline, $\mathrm{N}$-alkylated tetrahydroisoquinolines and their bioisosteres on polysaccharide-based chiral stationary phases. J Sep Sci. 2019;42:2779-87.

13. Ilisz I, Bajtai A, Szatmári I, Fülöp F, Lindner W, Péter A. Enantioseparation of $B$-carboline, tetrahydroisoquinoline and benzazepine analogues of pharmaceutical importance: Utilization of chiral stationary phases based on polysaccharides and sulfonic acid modified Cinchona alkaloids in high-performance liquid and subcritical fluid chromatography. J Chromatogr A. 2020;1615:460771.

14. Lee A, Choi HJ, Jin KB, Hyun MH. Liquid chromatographic resolution of 1-aryl-1,2,3,4-tetrahydroisoquinolines on a chiral stationary phase based on (+)-(18-crown-6)-2,3,11,12tetracarboxylic acid. J Chromatogr A. 2011;1218:4071-6.

15. Ilisz I, Grecsó N, Fülöp F, Lindner W, Péter A. Highperformance liquid chromatographic enantioseparation of cationic 1,2,3,4-tetrahydroisoquinoline analogs on Cinchona 
alkaloid-based zwitterionic chiral stationary phases. Anal Bioanal Chem. 2015;407:961-72.

16. Lipka E, Yous S, Furman C, Carato P, Deghaye C, Bonte JP, Vaccher C. Analytical and preparative chiral separation of $\beta$ carboline derivatives, LDL oxidation inhibitors, using HPLC and CE methodologies: Determination of enantiomeric purity. Chromatographia 2012;75:337-45.

17. Lajkó G, Grecsó N, Megyesi R, Forró E, Fülöp F, Wolrab D, Lindner W, Péter A, Ilisz I. Enantioseparation of ß-carboline derivatives on polysaccharide- and strong cation exchanger-based chiral stationary phases. A comparative study. J Chromatogr A. 2016;1467:188-98.

18. Allenmark S, Schurig V. Chromatography on chiral stationary phases. J Mater Chem. 1997;7:1955-63.

19. Sepsey A, Horváth É, Catani M, Felinger A. The correctness of van't Hoff plots in chiral and achiral chromatography. J Chromatogr A. 2020;1611:460594.

20. Asnin LD, Stepanova MV. Van’t Hoff analysis in chiral chromatography. J Sep Sci. 2018;41:1319-37.

21. Reshatova EN, Kopchenova MV, Vozisov SE, Vasyanin AN, Asnin LD. Enantioselective retention mechanism of dipeptides on antibiotic-based chiral stationary phases: Leucyl-leucine, glycyl-leucine, and leucyl-glycine as case studies. J Chromatogr A 2019;1602:368-77.

22. Asnin LD, Kopchenova MV, Vozisov SE, Klochkova MA, Klimova YA. Enantioselective retention mechanisms of dipeptides on antibiotic-based chiral stationary phases. II. Effect of the methanol content in the mobile phase. J Chromatogr A 2020;1626:461371.

23. Bajtai A, Tanács D, Berkecz R, Forró E, Fülöp F Lindner W, Péter A, Ilisz I. High-performance liquid chromatographic evaluation of strong cation exchanger-based chiral stationary phases focusing on stationary phase characteristics and mobile phase effects employing enantiomers of tetrahydro- $\beta$-carboline and 1,2,3,4-tetrahydroisoquinoline analogs. J Chromatogr A 2021;1644:462121.

24. Kovács B, Megyesi R, Forró E, Fülöp F. Efficient lipase-catalysed route for the kinetic resolution of salsolidine and its ß-carboline analogue. Tetrahedron Asymmetry 2017;28:1829-33.

25. Kovács B, Forró E, Fülöp F. Candida antarctica lipase B catalysed kinetic resolution of 1,2,3,4-tetrahydro- $\beta$-carbolines: Substrate specificity. Tetrahedron 2018;74:6873-7.
26. Grecsó N, Kohout M, Carotti A, Sardella R, Natalini B, Fülöp F, Lindner W, Péter A, Ilisz I. Mechanistic considerations of enantiorecognition on novel Cinchona alkaloid-based zwitterionic chiral stationary phases from the aspect of the separation of trans-paroxetine enantiomers as model compounds. J Pharm Biomed Anal. 2016;124:164-73.

27. Kopaciewicz W, Rounds MA, Fausnaugh J, Regnier F E. Retention model for high-performance ion-exchange chromatography. J Chromatogr A 1983;266:3-21.

28. Lajkó G, Orosz T, Grecsó N, Fekete B, Palkó M, Fülöp F, Lindner W, Péter A, Ilisz I. High-performance liquid chromatographic enantioseparation of cyclic $\beta$-aminohydroxamic acids on zwitterionic chiral stationary phases based on Cinchona alkaloids. Anal Chim Acta 2016;921:84-94.

29. Meyer A Y. Molecular mechanics and molecular shape. Part 4. Size, shape, and steric parameters. J Chem Soc Perkin Trans. 1986;2:1567.

30. Hoffmann CV, Reischl R, Maier NM, Lämmerhofer M, Lindner W. Investigations of mobile phase contributions to enantioselective anion- and zwitterion-exchange modes on quininebased zwitterionic chiral stationary phases. J Chromatogr A 2009;1216:1157-66.

\section{SUPPORTING INFORMATION}

Additional supporting information may be found online in the Supporting Information section at the end of the article.

How to cite this article: Tanács D, Bajtai A, Berkecz R, Forró E, Fülöp F, Lindner W, et al. Cinchona-alkaloid-based zwitterionic chiral stationary phases as potential tools for high-performance liquid chromatographic enantioseparation of cationic compounds of pharmaceutical relevance. J Sep Sci. 2021;44:2735-2743. https://doi.org/10.1002/jssc.202100264 